\title{
Nitrogen removal in recirculating aquaculture water with high dissolved oxygen conditions using the simultaneous partial nitrification, anammox and denitrification system
}

\author{
Jian $\mathrm{Lu}^{\mathrm{a}, \mathrm{b}, \mathrm{c}, *}$, Yuxuan Zhang ${ }^{\mathrm{a}, \mathrm{b}}$, Jun Wu ${ }^{\mathrm{d}}$, Jianhua Wang ${ }^{\mathrm{a}}$ \\ ${ }^{a}$ CAS Key Laboratory of Coastal Environmental Processes and Ecological Remediation, Yantai Institute of Coastal Zone Research (YIC), Chinese Academy of Sciences \\ (CAS), Shandong Key Laboratory of Coastal Environmental Processes, YICCAS, Yantai, Shandong 264003, PR China \\ ${ }^{\mathrm{b}}$ University of Chinese Academy of Sciences, Beijing 100049, PR China \\ ${ }^{\mathrm{c}}$ Center for Ocean Mega-Science, Chinese Academy of Sciences, 7 Nanhai Road, Qingdao 266071, PR China \\ ${ }^{\mathrm{d}}$ School of Resources and Environmental Engineering, Ludong University, Yantai, Shandong 264025, PR China
}

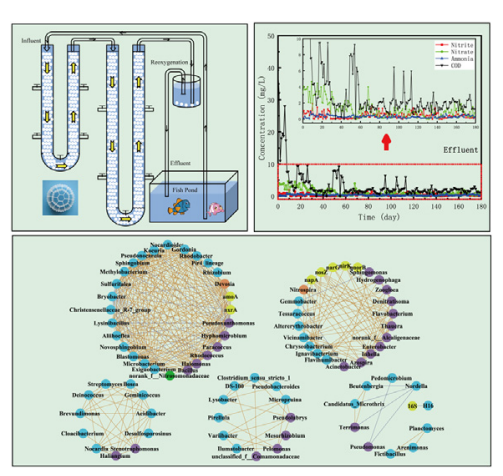

\section{A R T I C L E I N F O}

\section{Keywords:}

Bacterial community

SNAD

Nitrogen functional genes

Network analysis

Recirculating aquaculture system

\begin{abstract}
A B S T R A C T
The efficient removal of nitrogen pollutants in the aquaculture systems is still a challenge due to the low concentration of organic carbon and high concentration of dissolved oxygen (DO) in the wastewater. The simultaneous partial nitrification, anammox and denitrification (SNAD) bioreactor was firstly used for the treatment of aquaculture wastewater in recirculating aquaculture system. The bioreactor operated for 180 days without adding extra organic carbon. After 60-day operation, the bioreactor reached the stable stage with the average concentration of ammonia/nitrate/nitrite/COD in the effluent with $0.26 / 0.75 / 0.47 / 0.27 \mathrm{mg} / \mathrm{L}$. The Pseudoxanthomonas was the dominant genus in the biofilm samples. The typical nitrogen functional bacteria and genes for nitrification, anammox and denitrification were detected with different abundance in different procedures along the bioreactor. Network analysis revealed the significant correlations between nitrogen functional bacteria and genes. The SNAD bioreactor achieved the effective removal for nitrogen and COD under high DO conditions in recirculating aquaculture system.
\end{abstract}

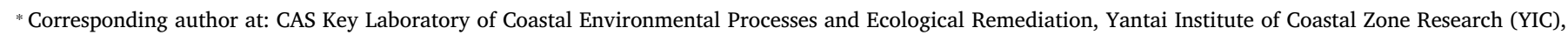
Chinese Academy of Sciences (CAS), Shandong Key Laboratory of Coastal Environmental Processes, YICCAS, Yantai, Shandong 264003, PR China.

E-mail address: jlu@yic.ac.cn (J. Lu). 


\section{Introduction}

Aquaculture, as one of the most important traditional industry, has been developed rapidly with the civil economy growth and the improvement of living standard (Wang et al., 2018a). However, severe pollutants have been generated from the aquaculture industry and discharged into natural environment, exerting a significant influence on environmental ecosystem and human health (Wang et al., 2018b, 2019a). The non-point pollution from aquaculture industry has been becoming a great issue for the water environment protection (Wang et al., 2018b). Therefore, efficient treatment for aquaculture wastewater is indispensable for the removal of contaminants (Kim et al., 2020). Typical aquaculture modes include the conventional (without recirculation unit) and recirculating systems (Wang et al., 2018b). The aquaculture wastewater in the recirculating aquaculture system (RAS) is circulated and reused after the systemic treatment while the wastewater in the conventional system without recirculation is discharged into coastal water directly or with simple treatment (Wang et al., 2018b). Recirculating aquaculture system has been an important approach for the control of the non-point pollution from aquaculture industry (Wang et al., 2019a). The accumulation of ammonium and nitrite which are high toxic substances for fish, shrimp and other aquatic organisms (Shao et al., 2019) will hinder the application of the RAS systems in the aquaculture industry. Therefore, the effective removal for nitrogen pollutants, especially ammonia and nitrite, is the key for the treatment of aquacultural wastewater. However, the efficient removal of nitrogen pollutants is still a challenge due to the low concentration of organic carbon and high concentration of dissolved oxygen (DO) of the wastewater in the aquaculture systems.

In traditional biotechnological process for decreasing nitrogen and chemical oxygen demand (COD), the nitrification and denitrification reactions were performed in separated reactors owing to the different demand of various functional microbial communities (Zhang et al., 2013). Therefore, a lot of advanced technologies have been developed for the removal of nitrogen with low carbon nitrogen ratio, such as SND (Simulation Nitrification and Denitrification) (Zhao et al., 2017), OLAND (Oxygen Limited Autotrophic Nitrification Denitrification) (Nhu Hien et al., 2017), SHARON (Single reactor for High Activity ammonia Removal Over Nitrite) (Claros et al., 2012) and CANON (Completely Autotrophic Nitrogen removal Over Nitrite) (Zhang et al., 2013). Meanwhile, anaerobic ammonium oxidation (anammox) have been widely applied to nitrogen removal (Zheng et al., 2019), which was an energy-saving process without extra organic electron donor that oxidized ammonium and nitrite to $\mathrm{N}_{2}$ (Wang et al., 2019b). The simultaneous partial nitrification, anammox and denitrification (SNAD) process has been developed to treat the wastewater with high concentration of nitrogen and low concentration of COD simultaneously (Keluskar et al., 2013; Wang et al., 2016; Wen et al., 2016). SNAD has been proven to be an efficient, economical and environmentally friendly process. Meanwhile, the SNAD process could protect the anammox process from being inhibited by organic carbon and DO (Jiang et al., 2018). As the biological oxidation of ammonia to nitrite and nitrate, nitrification is an effective approach for the removal of ammonia and organic contaminants (Jin et al., 2017). Under oxygen limitation, ammonia is oxidized to nitrite by ammonia oxidizing bacteria (AOB). The remaining ammonia and nitrite are removed by anammox process, followed by denitrification process contributed to the reduction of nitrite and nitrate to $\mathrm{N}_{2}$. As a consequence, nitrifiers, denitrifiers and anammox bacteria generally coexist and maintain harmony for the removal of nitrogen and organic carbon (Keluskar et al., 2013).

Aquaculture water often possesses high concentration of nitrogen (ammonia, nitrate and nitrite) and suspended particle as well as low concentration of COD (Shao et al., 2019). The SNAD process might be an effective technology for the treatment of wastewater with highconcentration nitrogen and low-concentration COD (Gao et al., 2013).
However, the anammox and denitrification processes could be inhibited under high-concentration DO conditions (Persson et al., 2014). DO concentration of aquaculture wastewater is usually high since oxygen is essential for the aquaculture animals, which is quite different from other wastewaters. Rare information is available on using SNAD system for treating water with high DO concentration in aquaculture systems. This study established a typical SNAD system for simultaneous removal of nitrogen and COD under high-concentration DO conditions in the recirculating aquaculture system. The removal efficiencies for nitrogen and COD were evaluated by daily monitoring the water quality parameters in the influent and effluent. In order to figure out the removal mechanism of contaminants, both the bacterial communities and the nitrogen functional bacteria (AOB, anammox and denitrifying bacteria) were further investigated.

\section{Materials and methods}

\subsection{Reactor system and operation strategy}

The SNAD bioreactor with the effective volume of $60 \mathrm{~L}$ was established using two parallel U-type tubes working as baffled biofilter and a reoxygenation tank serving as moving-bed biofilter (Fig. 1). The U-type tubes were filled by cylindrical plastic biofilter media (diameter of $25 \mathrm{~mm}$ ), which were cleaned by tap water directly. The bioreactor was equipped with a peristaltic pump for the recirculation of water. The hydraulic retention time (HRT) was set as $5 \mathrm{~h}$ and the influent flux was maintained in $12 \mathrm{~L} / \mathrm{h}$. An aerator was connected with the reoxygenation tank to maintain the high concentration of DO in the reoxygenation tank. For the start-up of the bioreactor, the effluent of the fish pond was introduced into the bioreactor. Subsequently, the water was circulated in the bioreactor and the fish ponds to form the recirculating system.

\subsection{Physicochemical analysis and removal performance}

The content of organic matter in the wastewater was expressed as COD. The concentrations of ammonia, nitrite, nitrate and COD were measured daily in accordance with the Standard Methods for the Examinations of Water and Wastewater. The total nitrogen (TN) represented the summation of ammonia $\left(\mathrm{NH}_{4}^{+}-\mathrm{N}\right)$, nitrite $\left(\mathrm{NO}_{2}^{-}-\mathrm{N}\right)$ and nitrate $\left(\mathrm{NO}_{3}^{-}-\mathrm{N}\right)$. The $\mathrm{pH}$ was analyzed using a $\mathrm{pH}$ meter (PHS-3C, INESA, China). DO level was measured by a portable DO meter (JPB607A, INESA, China) and suspended solid (SS) was determined by a multi-parameter water quality tester (5B-2H, Lianhua, China). Prior to

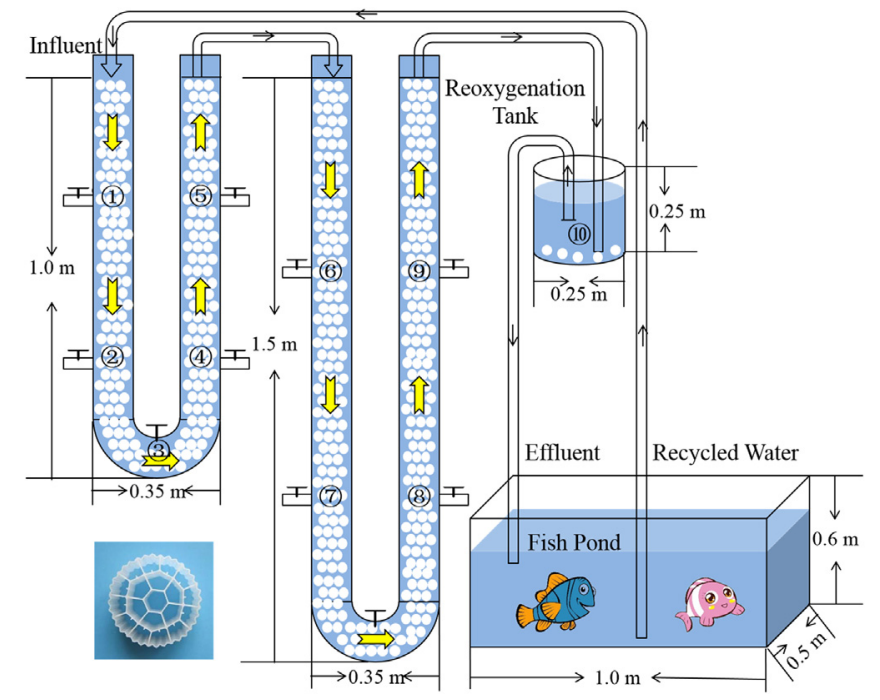

Fig. 1. Schematic diagram of the simultaneous partial nitrification, anammox and denitrification (SNAD) bioreactor in recirculating aquaculture system. 
the measurement of ammonia, nitrite and nitrate, water samples were filtered through $0.45 \mu \mathrm{m}$ mixed cellulose esters membranes (Merck Millipore Ltd, Ireland). Removal efficiencies of ammonia, nitrite, nitrate, TN and COD in the bioreactor were calculated by equation as the following:

Removal efficiency $=\frac{C_{i n f}-C_{e f f}}{C_{i n f}} \times 100 \%$

$C_{i n f}$ and $C_{\text {eff }}$ represented the concentration of nitrogen/COD in the influent and effluent of the bioreactor, respectively.

\subsection{Quantification of the microbial activity of SNAD biofilm}

The aerobic nitrite oxidation, anammox and denitrification activities of the SNAD biofilm in the biofilter were determined following the method of Zheng et al. (2016). Briefly, the plastic media with biofilm used in the batch tests were taken out from the SNAD bioreactor at the end of the experiment. The procedure for batch test was described in the methodology of Zheng et al. (2016). The batch tests were performed in $1000 \mathrm{~mL}$ flasks. $\mathrm{NH}_{4}{ }^{+}-\mathrm{N}\left(70 \mathrm{mg} \cdot \mathrm{L}^{-1}\right)$ and $\mathrm{NaHCO}_{3}\left(840 \mathrm{mg} \cdot \mathrm{L}^{-1}\right)$ were added for the AOB activity assay. $\mathrm{NH}_{4}{ }^{+} \mathrm{N}\left(70 \mathrm{mg} \cdot \mathrm{L}^{-1}\right)$ and $\mathrm{NO}_{2}{ }^{-}$$\mathrm{N}\left(70 \mathrm{mg} \cdot \mathrm{L}^{-1}\right)$ were mixed for the assay of anammox activity. $\mathrm{NO}_{2}{ }^{-}-\mathrm{N}$ $\left(70 \mathrm{mg} \cdot \mathrm{L}^{-1}\right)$ and $\mathrm{NaCH}_{3} \mathrm{COO}\left(520 \mathrm{mg} \cdot \mathrm{L}^{-1}\right)$ were mixed for denitrification activity assay. In the anammox and denitrification activity measurement system, the flasks were pumped with high-purity $\mathrm{N}_{2}$ gas (99.99\%) for $15 \mathrm{~min}$ to remove the oxygen before being sealed. In the case of the AOB activity assay, the flasks were purged with air at the flow rate of $250 \mathrm{~mL} \cdot \mathrm{min}^{-1}$, setting the DO $>5 \mathrm{mg} \cdot \mathrm{L}^{-1}$. All the assays were conducted at $30{ }^{\circ} \mathrm{C}$.

\subsection{Analysis of microbial communities}

Biofilm samples on the surface of plastic biofilter media were collected for DNA extraction by TIANamp Soil DNA Kit (TIANGEN Biotech, Beijing, China) according to manufacturer's instructions. The concentration, purity and quality of DNA were measured by a UV-vis spectrophotometer (NanoDrop Lite, Thermo Scientific, Wilmington, USA) and 1\% agarose gel electrophoresis. Purified microbial DNA extracted from biofilm samples were sent to Majorbio (Shanghai, China) for high-throughput sequencing. The V4-V5 regions of the bacterial 16S rRNA genes were selected for amplification by PCR system (GeneAmp 9700, ABI, USA), with a pair of primers 515F (5'-GTGCCAGCMGCCG CGG-3') and 907R (5'-CCGTCAATTCMTTTRAGTTT-3'). The PCR program and Illumina MiSeq Sequencing were carried out as reported in our previous research according to the standard protocols in Majorbio (Shanghai, China) (Zhang et al., 2020). Raw reads were deposited into the National Center for Biotechnology Information (NCBI) Sequence Read Archive (SRA) database (Accession Number: SRP229760).

\subsection{Quantification of nitrogen functional genes}

Eight nitrogen functional gene fragments were quantified by qPCR, including ammonia mono-oxygenase gene (amoA), nitrite oxidoreductase gene (nxrA), anammox bacteria (ANO 16S rRNA gene), membrane-bound nitrate reductase gene (narG), periplasmic nitrate reductase gene (napA), copper-containing nitrite reductase gene (nirK), nitric oxide reductase gene (qnorB) and nitrous oxide reductase gene (nosZ). All primer sequences have been listed in Table 1 as reported in previous publications (Braker and Tiedje, 2003; Ji et al., 2012).

The plasmid DNA was constructed by gene synthesis with the carrier of PMD-19 T. Calibration standard curves for absolute quantification were established by a ten-fold dilution series of plasmids DNA ranging from $10^{7}$ to $10^{0}$ copies/ $\mu \mathrm{L}$. All the plasmids DNA were run together with samples in triplicate. Each $10 \mu \mathrm{L}$ mixture for $\mathrm{qPCR}$ contained $1.0 \mu \mathrm{L}$ DNA template, $0.4 \mu \mathrm{L}$ forward primers $(0.4 \mu \mathrm{M}), 0.4 \mu \mathrm{L}$ reverse
Table 1

Primers for target nitrogen functional genes.

\begin{tabular}{|c|c|c|c|}
\hline \multirow{2}{*}{$\begin{array}{l}\text { Targets } \\
\text { amoA }\end{array}$} & \multicolumn{2}{|c|}{ Primer Sequence $\left(5^{\prime}-3^{\prime}\right)$} & \multirow{2}{*}{$\begin{array}{l}\begin{array}{l}\text { Amplicon } \\
\text { size/bp }\end{array} \\
120\end{array}$} \\
\hline & amo598f & GAATATGTTCGCCTGATTG & \\
\hline & amo718r & CAAAGTACCACCATACGCAG & \\
\hline \multirow[t]{2}{*}{$n x r A$} & $n x r A \mathrm{~F} 1$ & CAGACCGACGTGTGCGAAAG & 322 \\
\hline & $n x r A \mathrm{R} 1$ & TCYACAAGGAACGGAAGGTC & \\
\hline \multirow{2}{*}{$\begin{array}{r}\text { ANO } 16 S \\
\text { rRNA }\end{array}$} & AMX809F & GCCGTAAACGATGGGCACT & 257 \\
\hline & AMX1066R & AACGTCTCACGACACGAGCTG & \\
\hline \multirow[t]{3}{*}{$\operatorname{narG}$} & narG1960m2f & $\mathrm{TA}(\mathrm{CT}) \mathrm{GT}(\mathrm{GC})$ & 100 \\
\hline & & GGGCAGGA(AG)AAACTG & \\
\hline & narG $2050 \mathrm{~m} 2 \mathrm{r}$ & CGTAGAAGAAGCTGGTGCTGTT & \\
\hline \multirow[t]{2}{*}{ napA } & napA V17F & TGGACVATGGGYTTYAAYC & 152 \\
\hline & napA 4R & ACYTCRCGHGCVGTRCCRCA & \\
\hline \multirow[t]{2}{*}{ nirK } & nirK583F & TCATGGTGCTGCCGCGKGACGG & 326 \\
\hline & nirK909R & GAACTTGCCGGTKGCCCAGAC & \\
\hline \multirow[t]{2}{*}{ qnorB } & qnorB2F & GGNCAYCARGGNTAYGA & 262 \\
\hline & qnorB5R & ACCCANAGRTGNACNACCCACCA & \\
\hline \multirow[t]{2}{*}{ nosZ } & nosZ1527F & CGCTGTTCHTCGACAGYCA & 250 \\
\hline & nosZ1773R & ATRTCGATCARCTGBTCGTT & \\
\hline
\end{tabular}

primers $(0.4 \mu \mathrm{M}), 5.0 \mu \mathrm{L}$ SYBR Premix Ex Taq II (Takara, Dalian,

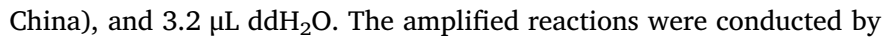
Bio-Rad qPCR system (Bio-Rad CFX384 Touch, USA) with the following program: denaturation at $95{ }^{\circ} \mathrm{C}$ for $30 \mathrm{~s}, 40$ cycles of $5 \mathrm{~s}$ at $95{ }^{\circ} \mathrm{C}$ and $30 \mathrm{~s}$ at $60^{\circ} \mathrm{C}$. Melting curves were conducted with temperature ranging from $60{ }^{\circ} \mathrm{C}$ to $95{ }^{\circ} \mathrm{C}$, and the melting curves with a single peak were considered as specific amplification. When the amplification efficiencies were in the range of $90 \%-110 \%$ and the $\mathrm{R}^{2}$ values of standard curves were higher than 0.99 , the reactions were taken into account for quantification of target genes as previous reports (Lu et al., 2020).

\subsection{Statistical analysis}

Statistical analysis and plotting were performed using Origin 2017 (Origin Lab Corporation, USA). Correlations were analyzed by SPSS 19 (IBM, USA) and the statistical tests were considered significant at $p<0.05$. Network analysis was performed in $R$ environment, and further visualized by Cytoscape 3.7.1.

\section{Results and discussion}

\subsection{Performance of the SNAD bioreactor in the recirculating aquaculture} system

The SNAD bioreactor in the recirculating aquaculture system was operated for 180 days. The temperature, $\mathrm{pH}$ and $\mathrm{DO}$ concentration of the effluent were controlled at $25-30{ }^{\circ} \mathrm{C}, 7.5-8.5$, and $7.0 \mathrm{mg} / \mathrm{L}$, respectively. The performance of COD, SS, DO, and C/N ratio of the reactor were showed in Fig. 2. The experimental period could be divided into three stages: Phase I, days 1-20; Phase II, 21-60; Phase III, 61-180. In the first 20 days, the concentrations of COD decreased significantly from $49.1 \mathrm{mg} / \mathrm{L}$ to $10.4 \mathrm{mg} / \mathrm{L}$ in the influent and from $39.1 \mathrm{mg} / \mathrm{L}$ to $6.9 \mathrm{mg} / \mathrm{L}$ in the effluent. The reactor showed high performance for the removal of COD. In the second phase, the COD level still presented obvious fluctuation. However, it demonstrated an overall decreasing tendency, with the maximum of $21.6 \mathrm{mg} / \mathrm{L}$ in the influent and $9.5 \mathrm{mg} / \mathrm{L}$ in the effluent. From day 61 to day 180 (Phase III), the lower concentration of COD varied from $0.9 \mathrm{mg} / \mathrm{L}$ to $9.7 \mathrm{mg} / \mathrm{L}$ in the influent and ranged from $0.6 \mathrm{mg} / \mathrm{L}$ to $6.4 \mathrm{mg} / \mathrm{L}$ in the effluent, indicating the effective removal for COD of the bioreactor. The performance of SS demonstrated that it gradually decreased from Phase I to Phase III and decreased from the influent to the effluent, at the average of $8.9 \mathrm{mg} / \mathrm{L}$ $(6.3 \mathrm{mg} / \mathrm{L}), 8.0 \mathrm{mg} / \mathrm{L}(4.0 \mathrm{mg} / \mathrm{L})$ and $6.2 \mathrm{mg} / \mathrm{L}(3.4 \mathrm{mg} / \mathrm{L})$ in the influent (effluent). The DO concentration was maintained in the range of 

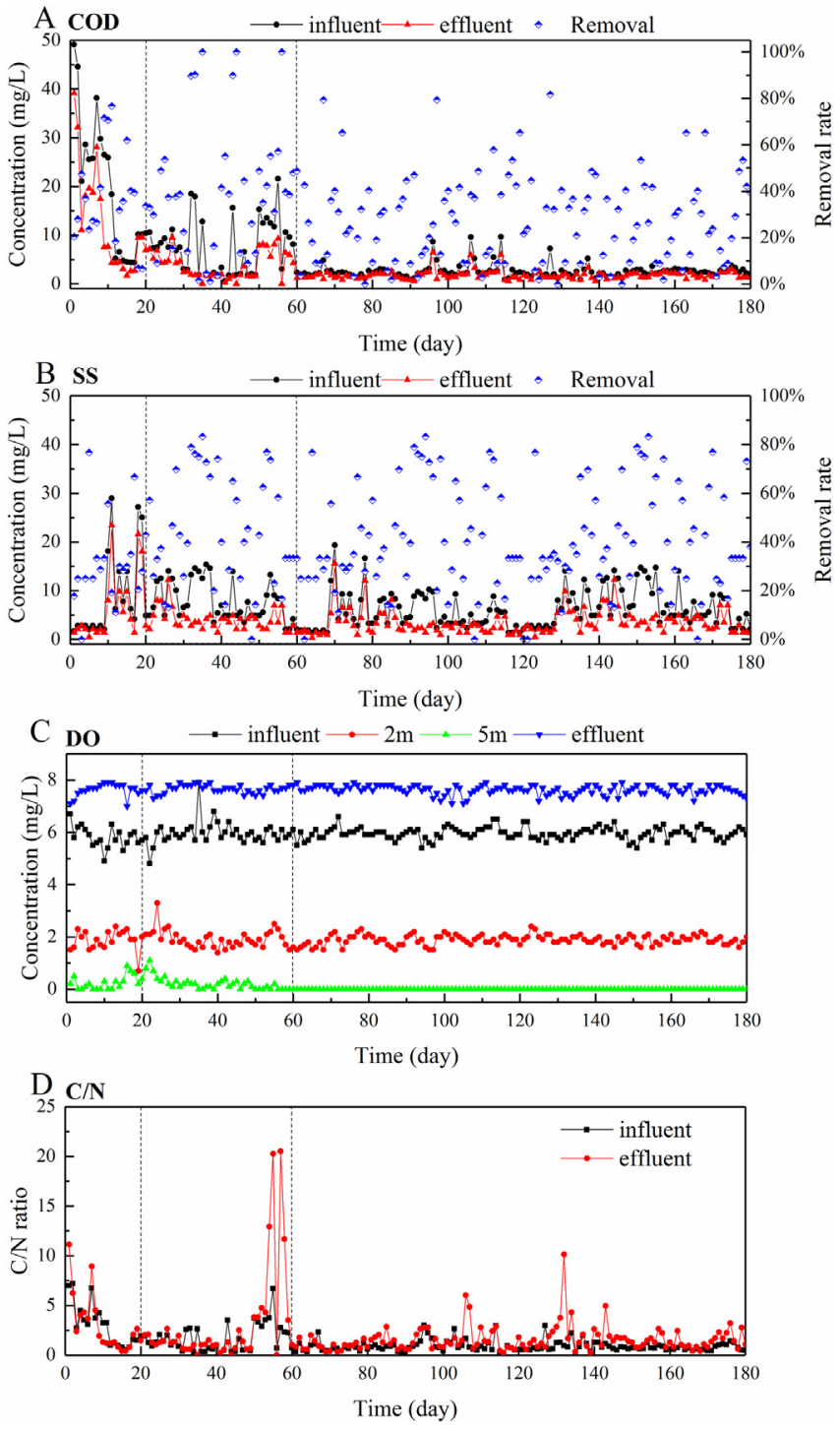

Fig. 2. The water treatment performance of the SNAD bioreactor on basic water quality parameters.

5-7 mg/L, followed by gradient descent in the effluent of U-type tube I ( $2 \mathrm{~m}, 1-3 \mathrm{mg} / \mathrm{L}$ ) and U-type tube II ( $5 \mathrm{~m}, 0-1 \mathrm{mg} / \mathrm{L}$ ). Subsequently, the DO concentration increased to $7-8 \mathrm{mg} / \mathrm{L}$ in the effluent of the bioreactor, which could provide adequate oxygen for the fish growth. Additionally, the low $\mathrm{C} / \mathrm{N}$ ratio in the system was appropriate for the removal of nitrogen in SNAD process.

In recent years, many countries and regions have enforced stringent discharge standards of nitrogen in aquacultural industry. It was urgent to develop eco-friendly and economical technologies for nitrogen removal. The SNAD process required the simultaneous activities of nitrification, anammox and denitrification, which both preferred to anoxic and anaerobic conditions (Gao et al., 2013). Therefore, the variation of DO created favorable conditions for nitrogen removal in the SNAD process. The SNAD bioreactor was constructed with the advantages of short process flow, fewer equipment, and lower energy consumption. It was performed in natural conditions without the addition of extra carbon. Wastewater from the fish ponds flowed through the aerobic zone, anoxic zone, anaerobic environment and re-aerobic environment in the SNAD bioreactor. The system provided suitable environment for the breeding of diverse functional bacteria and genes by the variation of aerobic-anoxic-anaerobic conditions. Additionally, the plastic biofilter media in the bioreactor were excellent carriers for
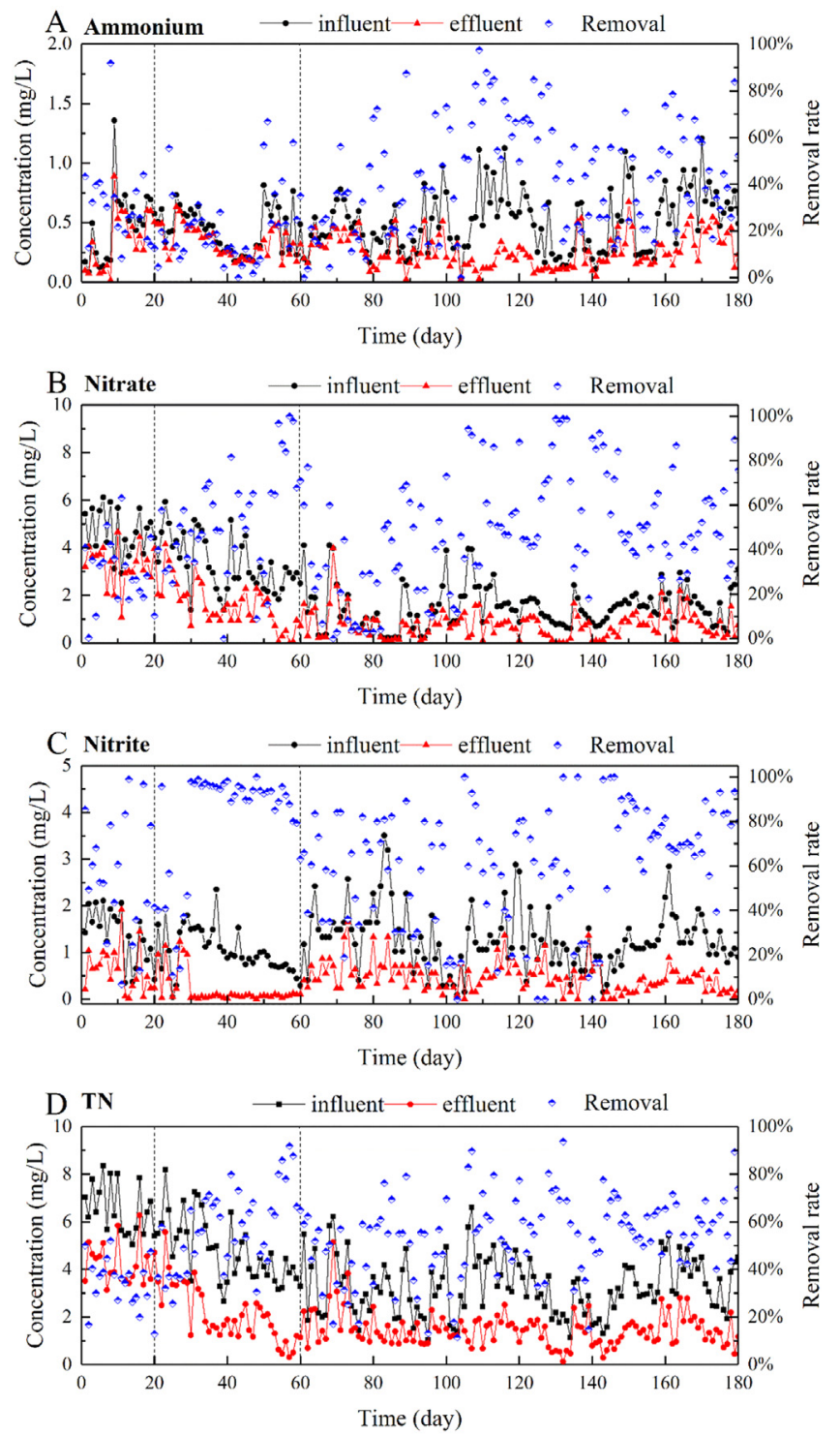

Fig. 3. The performance of ammonia (A), nitrate (B), nitrite (C) and total nitrogen (TN).

the breeding of bacteria, as plastic biofilter media was suitable for forming biofilm (Cimbritz et al., 2019). They were filled into the reactor, implementing a separation of gas-liquid-solid phase, maintaining biofilms for succession of microorganisms, and resulting in the coexistence of aerobic and anaerobic environment. As a result, the SNAD bioreactor provided the alteration of aerobic-anoxic-anaerobic environment and gas-liquid-solid phase for the breeding of bacteria. It was an efficient and economical approach for water treatment under high DO conditions in the recirculating aquaculture system.

\subsection{Nitrogen removal of the SNAD bioreactor}

The performance of nitrogen removal was exhibited in Fig. 3. In Phase I, ammonia concentration in the influent was up to $1.36 \mathrm{mg} / \mathrm{L}$, and it decreased to $0.50 \mathrm{mg} / \mathrm{L}$ on day 20 . In the effluent, the concentration of ammonia maintained in the range of $0.02 \mathrm{mg} / \mathrm{L}$ to $0.89 \mathrm{mg} / \mathrm{L}$. The highest removal efficiency of ammonia reached $92 \%$. For nitrate, the maximum concentration was $6.11 \mathrm{mg} / \mathrm{L}$ in the influent, while it decreased to $4.66 \mathrm{mg} / \mathrm{L}$ in the effluent. The removal rate of nitrate reached to $63 \%$, resulting in the lower nitrate concentration in the effluent. The nitrite concentration in the influent decreased from 
$2.07 \mathrm{mg} / \mathrm{L}$ to $0.42 \mathrm{mg} / \mathrm{L}$ on day 20 and it varied from $0.01 \mathrm{mg} / \mathrm{L}$ to $1.92 \mathrm{mg} / \mathrm{L}$ in the effluent, indicating that the nitrite removal efficiency could reach $99 \%$. After 20-day operation, the TN concentration in the influent decreased stepwisely to $5.41 \mathrm{mg} / \mathrm{L}$, while that in the effluent was lower with $4.71 \mathrm{mg} / \mathrm{L}$. In Phase II (from day 20 to day 60), the nitrogen descended by the time and tended to be stable. The influent ammonia concentration decreased gradually from 0.5 to $0.6 \mathrm{mg} / \mathrm{L}$ to $0.2-0.5 \mathrm{mg} / \mathrm{L}$, while the effluent ammonia concentration ranged from 0.1 to $0.4 \mathrm{mg} / \mathrm{L}$ during day 55 to day 60 . At the end of Phase II, the concentrations of nitrate and nitrite reduced to $2.50 / 0.73 \mathrm{mg} / \mathrm{L}$ and $0.29 / 0.11 \mathrm{mg} / \mathrm{L}$ in the influent/effluent, respectively. The removal efficiencies of ammonia, nitrate, nitrite and TN reached $67 \%, 100 \%$, $100 \%$ and $92 \%$. After running for 60 days, the bioreactors arrived at the stable stage (Phase III). The influent ammonia, nitrate and nitrite concentrations were almost lower than $0.8 \mathrm{mg} / \mathrm{L}, 3.0 \mathrm{mg} / \mathrm{L}$ and $1.5 \mathrm{mg} /$ $\mathrm{L}$, respectively. The bioreactor held significant effect for the removal of nitrogen at the stable state, maintaining the average concentration of ammonia, nitrate and nitrite in the effluent at $0.26 \mathrm{mg} / \mathrm{L}, 0.75 \mathrm{mg} / \mathrm{L}$ and $0.47 \mathrm{mg} / \mathrm{L}$, which were suitable for the subsistence of fish.

In the B1 biofilm with high DO concentrations, the anammox activity, denitrification activity, and aerobic nitrite oxidation activity were $0.186\left(\mathrm{~kg} \mathrm{TIN} \mathrm{kg} \mathrm{VSS}^{-1} \mathrm{~d}^{-1}\right), 0.143\left(\mathrm{~kg} \mathrm{NO}_{2}{ }^{-}-\mathrm{N} \mathrm{kg} \mathrm{VSS}^{-1} \mathrm{~d}^{-1}\right)$, and $0.241\left(\mathrm{~kg} \mathrm{NO}_{2}{ }^{-}-\mathrm{N} \mathrm{kg} \mathrm{VSS}^{-1} \mathrm{~d}^{-1}\right)$, respectively. In the B5 biofilm with moderate DO concentration, the anammox activity, denitrification activity, and aerobic nitrite oxidation activity were 0.217 ( $\mathrm{kg}$ TIN kg $\left.\mathrm{VSS}^{-1} \mathrm{~d}^{-1}\right), 0.178\left(\mathrm{~kg} \mathrm{NO}_{2}{ }^{-}-\mathrm{N} \mathrm{kg} \mathrm{VSS}^{-1} \mathrm{~d}^{-1}\right)$, and $0.159\left(\mathrm{~kg} \mathrm{NO}_{2}{ }^{-}-\mathrm{N}\right.$ $\left.\mathrm{kg} \mathrm{VSS}{ }^{-1} \mathrm{~d}^{-1}\right)$, respectively. In the B9 biofilm with low DO concentrations, the anammox activity, denitrification activity, and aerobic nitrite oxidation activity were $0.269\left(\mathrm{~kg}^{\mathrm{TIN}} \mathrm{kg} \mathrm{VSS}^{-1} \mathrm{~d}^{-1}\right), 0.211(\mathrm{~kg}$ $\mathrm{NO}_{2}{ }^{-}-\mathrm{N} \mathrm{kg} \mathrm{VSS}^{-1} \mathrm{~d}^{-1}$ ), and $0.091\left(\mathrm{~kg} \mathrm{NO}_{2}{ }^{-}-\mathrm{N} \mathrm{kg} \mathrm{VSS}^{-1} \mathrm{~d}^{-1}\right)$, respectively. The concentration of DO has great influence on the nitrogen removal process. The anammox and denitrification activity increased while the aerobic nitrite oxidation decreased in the SNAD bioreactor where DO concentration decreased. However, the anammox and denitrification were not totally inhibited under high DO concentrations in this system. The inhibition of high DO on these anaerobic bioprocesses might be alleviated by the biofilm on the biofilter media (Zheng et al., 2016). Consequently, the SNAD bioreactor presented high performance for nitrogen removal to make the nitrogen contents meet the fishery water quality standards for fish growth.

\subsection{Microbial community structure of the SNAD bioreactor}

The microbial communities of the biofilm on the surface of SNAD bioreactor media were investigated (Table 2). The higher Shannon value and the lower Simpson value, the higher community diversity (Wen et al., 2016). The result demonstrated that community diversity in anoxic environment (B5 and B9) was higher than that in aerobic environment (B1 and B10). The Sobs, Ace and Chao1 estimators were used to estimate the community richness based on OTU number. These values demonstrated that the community richness of the biofilm samples collected from the bioreactor decreased stage by stage with the water flow direction, from the influent to the effluent (B1 to B10).

As shown in Fig. 4A, a total of 24 phyla were detected in these biofilm samples. Approximately $43.8 \%, 74.2 \%, 60.6 \%$ and $52.0 \%$ of the sequences were assigned into Proteobacteria in B1, B5, B9 and B10,

Table 2

Diversity and richness estimators of bacterial communities in the bioreactor.

\begin{tabular}{llllllll}
\hline Sample & Shannon & Simpson & Sobs & Ace & Chao1 & Coverage & Seq_num \\
\hline B1 & 3.03 & 0.1144 & 410 & 458.09 & 463.37 & 0.9982 & 61,324 \\
B5 & 3.19 & 0.0929 & 390 & 425.40 & 434.25 & 0.9985 & 55,045 \\
B9 & 3.27 & 0.0938 & 384 & 405.67 & 411.50 & 0.9989 & 42,215 \\
B10 & 3.10 & 0.1083 & 321 & 357.79 & 358.66 & 0.9987 & 45,036 \\
\hline
\end{tabular}

respectively. However, the relative abundance of other phyla varied significantly in different biofilm samples. In the biofilm sample of B1, Bacteroidetes accounted for $41.1 \%$, followed by Chloroflexi $(5.2 \%)$, Actinobacteria $(2.8 \%)$ and Acidobacteria (2.3\%). The difference was that Chloroflexi (12.5\%) was the secondary abundant phylum in B5, followed by Actinobacteria (6.3\%) and Acidobacteria (2.0\%). The relative abundances of Chloroflexi (15.6\%) and Bacteroidetes (12.2\%) were second to the phylum of Proteobacteria in B9. On the contrary, there was obvious difference in the sample of B10, in which Firmicutes (21.3\%) and Actinobacteria (19.3\%) were detected with higher abundances. Similar dominant phyla were determined in previous reports (Zheng et al., 2019). Besides the DO concentration in different sampling points, the distribution and abundance of microorganisms, nitrogen, organics, etc., seemed also responsible for the bacterial community structure in the SNAD bioreactor. According to previous studies, the filamentous bacteria (Firmicutes, Bacteroidetes, Chloroflexi, etc.) with rapid growth rate were significant builders for backbones within bioflocs, implying their competence in the removal of organic matter under substrate limiting conditions (Guo and Zhang, 2012).

A total of 298 genera were detected and identified in the biofilm samples, and the dominant genera were listed in Fig. 4B. Pseudoxanthomonas, Acinetobacter, Lysobacter, Exiguobacterium, Pseudomonas, Gemmobacter and Cloacibacterium were the dominant genera in the biofilm samples, with the average of relative abundances at $14.4 \%$, $9.4 \%, 6.1 \%, 5.3 \%, 5.2 \%, 4.9 \%$ and $3.9 \%$, respectively. However, the relative abundances of these genera differed in different samples. Pseudoxanthomonas, Gemmobacter and Pseudomonas were detected with higher relative abundance in B1, while Lysobacter, Pseudoxanthomonas, Pseudomonas and Gemmobacter accounted for higher percentage in B5. The top four dominant genera in B9 were Pseudoxanthomonas, Acinetobacter, Cloacibacterium and Lysobacter, while Acinetobacter and Exiguobacterium were the dominant genera in B10. Bacterial community structures were significantly different due to the different concentration of DO, nitrogen, COD, and so on. Different processes in the bioreactor presented great impact on bacterial communities, resulting in the shift of dominant bacteria following the wastewater treatment processes.

\subsection{Functional bacteria of the SNAD bioreactor}

Some nitrogen functional bacteria, including the nitrifying bacteria, anammox bacteria and denitrifying bacteria, were detected in this system. As shown in Fig. 5A \& B, both $\mathrm{AOB}$ and NOB existed in the system, and NOB were detected with higher relative abundance in B10 $(0.12 \%)$ and B1 $(0.05 \%)$. However, the relative abundance of AOB was at the same level $(0.04 \%)$ in different biofilm samples, which played important roles in the spatial nitrification process with limited oxygen. Nitrospirae was detected in B1 with the percentage of $0.04 \%$, playing an important role in the ammonia oxidizing bacteria. Furthermore, the phylum of Planctomycetes, which was affiliated with anammox bacteria (Wang et al., 2019b), increased from the aerobic environment (1.0\% of B1 and $1.0 \%$ of B10) to the anoxic environment $(1.1 \%$ of B5 and $1.5 \%$ of B9). After 180-day operation, the order of Planctomycetales became dominant and played a vital role in the anammox process in the biofilter system, with higher abundance in B5 and B9 (1.0\% and 1.4\%) than $\mathrm{B} 1$ and $\mathrm{B} 10(0.9 \%$ and $0.8 \%)$. The result further confirmed that the anoxic condition was more suitable for the breeding and enrichment of anammox bacteria.

The presence of COD enabled the survival of denitrifiers, and the denitrifying bacteria were assigned to the phyla of Proteobacteria, Actinobacteria, Bacteroidetes and Firmicutes. The impact of COD concentration in the influent on the shift of microbial communities was mainly mediated by the heterotrophic bacteria. The phylum of Bacteroidetes has been proven to be related to the degradation of organic carbon (Ding et al., 2018). It was detected with higher relative abundance in B1, in which the COD and DO concentrations were higher. The dominant phylum, Proteobacteria, was partially identified 

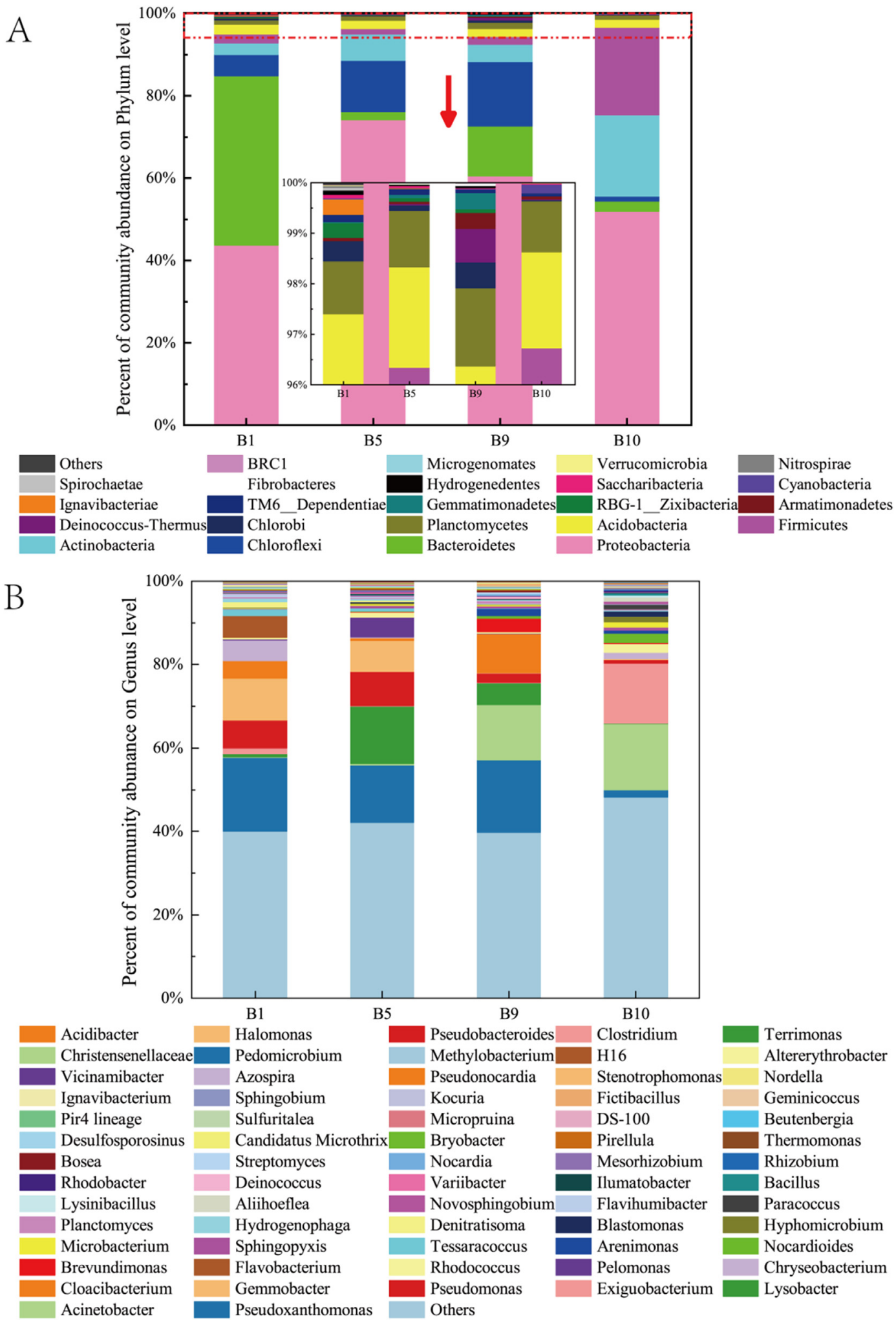

Fig. 4. Bacterial communities on phylum level (A) and on genus level (B).

as nitrogen-fixation bacteria (Wen et al., 2016) and affiliated with AOB (Nitrosomonadaceae), NOB (Nitrospira and Devosia), and denitrifiers. Chloroflexi was speculated as scavengers of organic matter derived from anammox bacteria. Most members of Acidobacteria and Chlorobi were autotrophic bacteria and anaerobic bacteria. Furthermore, the bacteria responsible for heterotrophic denitrification and autotrophic denitrification were identified in Chlorobi and Chloroflexi, with higher relative abundance in the anoxic environment (B5 and B9).

The genera of Pseudoxanthomonas, Acinetobacter and Pseudomonas were predominant as denitrifiers in this system. Other genera of denitrifiers were demonstrated in Fig. 5A \& B. On the whole, the detected denitrifiers, including aerobic denitrifying bacteria and anaerobic denitrifying bacteria, presented a high relative abundance in the biofilm samples. The denitrifiers accounted for $40.2 \%$ and $37.6 \%$ in the anoxic 

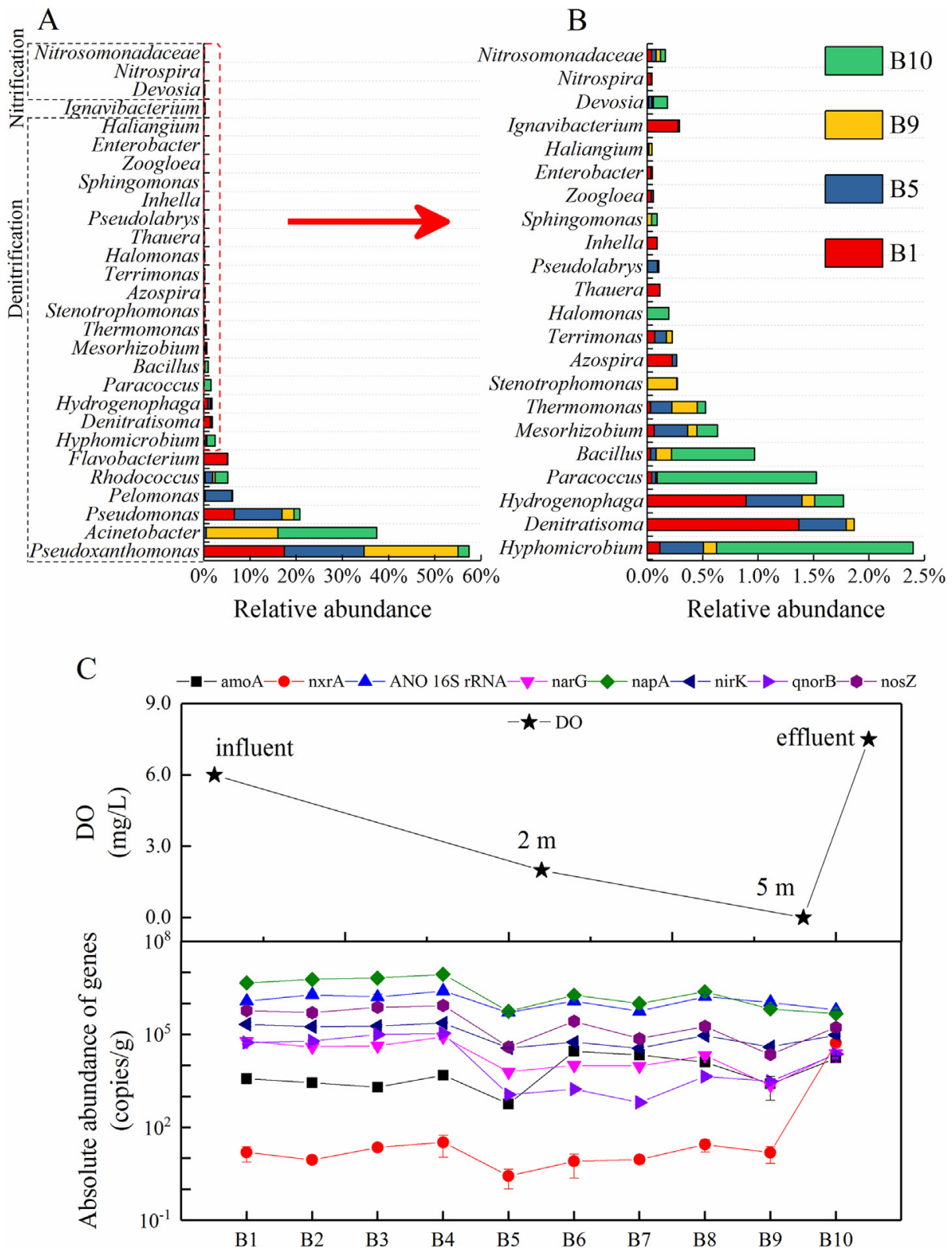

Fig. 5. The relative abundance of nitrogen functional bacteria (A \& B) and absolute abundance nitrogen functional genes (C) of the SNAD bioreactor in the recirculating aquaculture system.

environment (B9 and B5), while the percentages of them in the aerobic environment were lower (B1 of $32.8 \%$ and B10 of 32.9\%). To our knowledge, the genera of Acinetobacter, Pseudomonas, Rhodococcus, Paracoccus, Bacillus, Mesorhizobium, Stenotrophomonas, Halomonas, Thauera, Enterobacter were important denitrifiers possessing abilities of heterotrophic nitrification and aerobic denitrification (HN-AD) as previous reports (Lu et al., 2008; Thakur and Medhi, 2019). Interestingly, most of the HN-AD bacteria were detected with higher relative abundance in the aerobic conditions (B1 and B10). Overall, the special bacterial structure provided an appropriate environment for the functional bacteria, and guaranteed the good performance for nitrogen removal.

In the SNAD process, the functional bacteria played important roles in the removal of nitrogen and COD (Zheng et al., 2019). Wastewater from the fish ponds was the source for the inoculation of functional bacteria to the bioreactor. As shown in the schematic diagram of the experimental equipment, B1, B5, B9 and B10 were located in different processes in the bioreactor to hold different functional microbial communities. In addition, the plastic biofilter media filters filled in the bioreactor could be considered as micro-reactors, with different microbial communities in the inside and outside surface of the biofilm on the carriers. Consequently, the nitrifying bacteria, anammox bacteria and denitrifying bacteria, autotrophic bacteria and heterotrophic bacteria, as well as aerobic bacteria and anaerobic bacteria could be coexistent and synergistic in the SNAD system for the removal of nitrogen.

\subsection{Nitrogen functional genes of the SNAD bioreactor}

Real-time PCR quantified the absolute abundance of nitrogen functional genes, including genes involved in nitrogen transformation of nitrification (amoA and nxrA), anammox (ANO 16S rRNA gene) and denitrification (narG, napA, nirK, qnorB and nosZ) (Fig. 5C). In the nitrification process, amoA was a marker involved in ammonia oxidation to nitrite, and nxrA was a marker involved in nitrite oxidation to nitrate. ANO 16S rRNA gene, as a marker for anammox process, was involved in the transformation of ammonia and nitrite to nitrogen gas. As 
previously reported, the denitrification process was divided into four steps. Both napA and narG were involved in the first step (nitrate to nitrite), nirK was a marker for the second step (nitrite to nitric oxide), qnorB was a marker involved in the third step (nitric oxide to nitrous oxide), and nosZ was involved in the last step (nitrous oxide to nitrogen gas) (Ji et al., 2012).

All the target functional genes were detected in the biofilm samples and the absolute abundances of these genes remained relatively stable from B1 to B4. The absolute abundance of napA was maintained at the highest level $\left(4.6 \times 10^{6}\right.$ copies $/ g-8.7 \times 10^{6}$ copies $\left./ g\right)$, while that of narG was relatively lower $\left(4.0 \times 10^{4}\right.$ copies $/ g-8.5 \times 10^{4}$ copies $\left./ g\right)$. The abundance of ANO $16 \mathrm{~S}$ rRNA gene $\left(1.2 \times 10^{6}\right.$ copies/g-2.5 $\times 10^{6}$ copies/g) was second to napA, while the abundance of nxrA was the lowest. The gene of amoA was detected with the absolute abundance in the range of $2.0 \times 10^{3}$ copies/g-4.9 $\times 10^{3}$ copies/g from B1 to B4, while $n x r$ A was detected with the absolute abundance ranging from 8.9 copies/g to 33.3 copies/g. The gene of $n x r$ A exhibited a similar variation trend to amoA with lower abundance. In the biofilm samples of B5, the absolute abundance of target genes decreased significantly due to the reduction of substrates (organic carbon and $\mathrm{N}$ compounds) in the tailing water, while it increased to higher level in the biofilm samples from B6 to B9. The absolute abundance of amoA increased significantly in the samples from B6 to B9, as a result of the appropriate DO concentration for the partial nitrification reaction. It was important to note that the abundance of ANO 16S rRNA gene exceeded napA under strictly anaerobic conditions (B9). At B10, all the target genes reached equal level with the absolute abundance higher than $10^{4}$ copies $/ g$.

The simultaneous partial nitrification, anammox and denitrification systems were highly effective process to remove nitrogen. Nitrogen functional genes played important roles in the removal of nitrogen and they acted as important indicators for nitrogen removal ability. Despite the variation of DO concentration along the bioreactor, all the target nitrogen functional genes were detected in the biofilm samples. The different abundance of narG and napA might be attributed to the nitrogen functional bacterial communities, in which denitrifying bacteria accounted for the largest proportion. Additionally, narG played dominant roles under hypoxic conditions, while napA played significant roles both under aerobic and anoxic conditions (Huang et al., 2017). It was further confirmed that denitrification acted as a vital pathway for the removal of nitrogen in the SNAD process. In addition, owing to the appropriate enhancement of the anaerobic or anoxic environment in the bioreactor, the absolute abundance of denitrification functional genes increased slightly due to the shortage of extra organics. The abundance of ANO 16S rRNA gene was higher than the nxrA gene, indicating that the anammox reaction preceded the nitrite oxidation in the SNAD process. The similar environmental conditions and ecological interactions by $\mathrm{AOB}$ and $\mathrm{NOB}$ resulted in the similar variation pattern of amoA and $n x r \mathrm{~A}$. Furthermore, the lower abundance of $n x r \mathrm{~A}$ might be attributed to the nitrification process and the competitive advantages of AOB (Wang et al., 2017).

\subsection{Co-occurrence patterns of nitrogen functional bacteria and genes}

Co-occurrence patterns between the dominant bacterial communities, nitrogen functional bacteria and nitrogen functional genes were investigated by network analysis. Connections with significant and strong correlations $(\mathrm{p}<0.05$, Pearson's correlation coefficient $>0.9$ ) have been taken into account for further analysis. Fig. 6A exhibited the correlations between nitrogen functional genes and the bacterial communities on phylum level. There were close correlations between denitrification genes (narG, napA, nirK, qnorB and nirK), and the nitrification gene of amoA was closely related to nxrA. The phyla of Bacteroidetes, Acidobacteria, RBG-1_Zixibacteria, Ignavibacteriae, Spirochaetae and Nitrospirae were assigned to napA, and Ignavibacteriae was assigned to nosZ. The phyla of Firmicutes, Cyanobacteria and BRC1 were assigned to amoA, and Actinobacteria, Firmicutes, Cyanobacteria and
BRC1 were assigned to nxrA. Additionally, there were positive and significant correlations between the bacteria in different phyla, indicating the close connections between different functional bacteria for nitrogen removal.

The correlations between nitrogen functional genes and bacterial communities on genus level were demonstrated in Fig. 6B. The network analysis was performed based on the dominant bacteria (top 50 genera), nitrogen functional bacteria (30 genera) and nitrogen functional genes. A total of 391 pairs of significant correlations were identified involving 8 connections of gene \& gene, 63 connections of gene \& bacteria and 320 connections of bacteria \&bacteria. Total 16 bacterial genera were assigned to $a \mathrm{moA}$ and 20 genera were assigned to $n x r \mathrm{~A}$. The representative nitrification bacteria Devosia have positive and significant correlations with amoA and nxrA. Furthermore, 26 genera were significantly correlated with the target denitrification genes, including amounts of typical denitrification bacteria, Denitratisoma, Enterobacter, Flavobacterium, Inhella and Thauera, for instance.

Co-occurrence patterns between target genes and microbial taxa could indicate the possible host information, if the target genes and the co-existed microbial taxa possessed the significantly similar abundance trends among different samples ( $\mathrm{Lu}$ et al., 2020). Therefore, the network analysis has been utilized to reveal the correlations between the target nitrogen functional genes and bacteria, and the potential host bacteria of nitrogen functional genes. Complicated strong and significant correlations were identified between different nitrogen functional genes and bacteria on phylum and genus level, for example, gene \& gene, gene \& bacteria, and bacteria \& bacteria. According to previous reports, the aggregated growth was a favorite way for anammox bacteria and the competing of denitrification and anammox could promote the agminate growth of anammox bacteria (Gao et al., 2012). Nitrification, anammox and denitrification reaction in this SNAD bioreactor were the dominant nitrogen removal pathways. Owing to the coexistence of aerobic, anaerobic and anoxic environment, the SNAD bioreactor achieved high performance of nitrogen removal for treating aquaculture wastewater in the recirculating aquaculture system. The combined actions of nitrogen functional bacteria and nitrogen functional genes were crucial and indispensable for the removal of nitrogen, resulting in the effective removal for ammonia, nitrite and nitrate in the SNAD process.

\section{Conclusions}

The SNAD system for simultaneous removal of nitrogen and COD under high DO conditions was established in the recirculating aquaculture system. The bioreactor achieved high-efficient removal for nitrogen and COD in spontaneous environment. The typical nitrogen functional bacteria and genes for nitrification, anammox and denitrification were detected with different abundances in different procedures along the bioreactor. Complicated strong and significant correlations between nitrogen functional bacteria and genes were identified. The SNAD bioreactor achieved effective removal for nitrogen and COD under high DO conditions in the recirculating aquaculture system with the cooperation of nitrogen functional bacteria and genes.

\section{CRediT authorship contribution statement}

Jian Lu: Conceptualization, Data curation, Funding acquisition, Investigation, Methodology, Project administration, Supervision, Resources, Writing - original draft, Writing - review \& editing. Yuxuan Zhang: Formal analysis, Investigation, Methodology, Writing - original draft. Jun Wu: Methodology, Investigation, Software, Writing - review \& editing. Jianhua Wang: Formal analysis.

\section{Declaration of Competing Interest}

The authors declare that they have no known competing financial 


\section{A. Phylum}

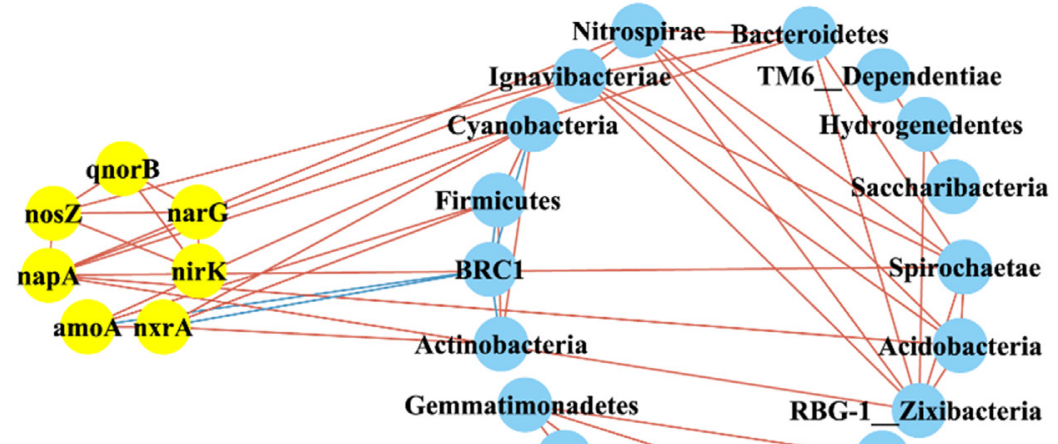

Deinococcus-Thermus Armatimonadetes

FibrobacteresPlanctomycetes

\section{B. Genus}

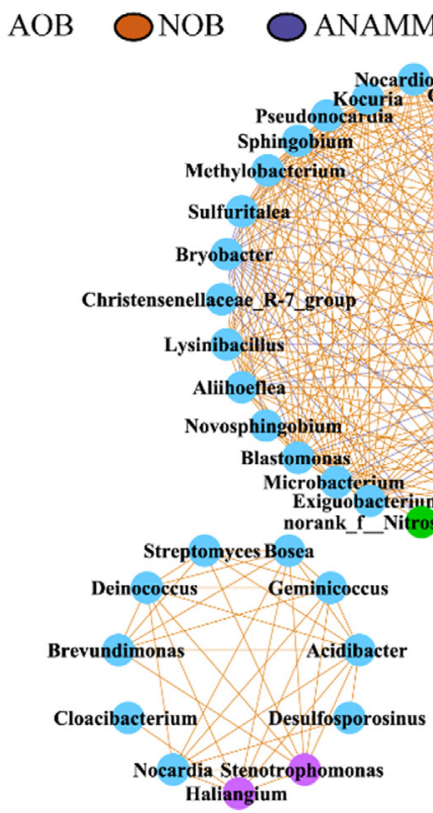

Denitrification

$\bigcirc$ Nitrogen functional genes

Other genera

Fig. 6. Network analysis between nitrogen functional bacteria and genes on phylum level (A) and on genus level (B).

interests or personal relationships that could have appeared to influence the work reported in this paper.

\section{Acknowledgements}

This work was supported by National Natural Science Foundation of China (41877131), Taishan Scholars Program of Shandong Province (No. tsqn201812116), One Hundred Talents Program of Chinese Academy of Sciences (Y629041021), Science and Technology Service Network Initiative of the Chinese Academy of Sciences (KFJ-STS-QYZX114), and Two-Hundred Talents Plan of Yantai (Y739011021).

\section{References}

Braker, G., Tiedje, J.M., 2003. Nitric oxide reductase (norB) genes from pure cultures and environmental samples. Appl. Environ. Microbiol. 69 (6), 3476.

Cimbritz, M., Edefell, E., Thörnqvist, E., El-taliawy, H., Ekenberg, M., Burzio, C., Modin, O., Persson, F., Wilén, B.-M., Bester, K., Falås, P., 2019. PAC dosing to an MBBR effects on adsorption of micropollutants, nitrification and microbial community. Sci. Total. Environ. 677, 571-579.

Claros, J., Serralta, J., Seco, A., Ferrer, J., Aguado, D., 2012. Real-time control strategy for nitrogen removal via nitrite in a SHARON reactor using $\mathrm{pH}$ and ORP sensors. Process Biochem. 47 (10), 1510-1515.

Ding, S.Z., Bao, P., Wang, B., Zhang, Q., Peng, Y.Z., 2018. Long-term stable simultaneous partial nitrification, anammox and denitrification (SNAD) process treating real domestic sewage using suspended activated sludge. Chem. Eng. J. 339, 180-188. Gao, F., Zhang, H.M., Yang, F.L., Qiang, H., Li, H.J., Zhang, R., 2013. Study of an innovative anaerobic (A)/oxic (O)/anaerobic (A) bioreactor based on denitrification-anammox technology treating low $\mathrm{C} / \mathrm{N}$ municipal sewage. Chem. Eng. J. $232,65-73$.

Gao, F., Zhang, H.M., Yang, F.L., Qiang, H., Zhang, G.Y., 2012. The contrast study of anammox-denitrifying system in two non-woven fixed-bed bioreactors (NFBR) treating different low C/N ratio sewage. Bioresour. Technol. 114, 54-61.

Guo, F., Zhang, T., 2012. Profiling bulking and foaming bacteria in activated sludge by high throughput sequencing. Water Res. 46 (8), 2772-2782.

Huang, M.L., Wang, Z., Qi, R., 2017. Enhancement of the complete autotrophic nitrogen removal over nitrite process in a modified single-stage subsurface vertical flow constructed wetland: effect of saturated zone depth. Bioresour. Technol. 233, 191-199.

Ji, G.D., Wang, R.J., Zhi, W., Liu, X.X., Kong, Y.P., Tan, Y.F., 2012. Distribution patterns of denitrification functional genes and microbial floras in multimedia constructed wetlands. Ecol. Eng. 44, 179-188.

Jiang, H.C., Liu, G.H., Ma, Y.M., Xu, X.L., Chen, J.H., Yang, Y.Q., Liu, X.H., Wang, H.C., 2018. A pilot-scale study on start-up and stable operation of mainstream partial nitrification-anammox biofilter process based on online pH-DO linkage control. Chem. Eng. J. 350, 1035-1042.

Jin, Q., Lu, J., Wu, J., Luo, Y.M., 2017. Simultaneous removal of organic carbon and nitrogen pollutants in the Yangtze estuarine sediment: the role of heterotrophic nitrifiers. Estuar. Coast. Shelf. S. 191, 150-156.

Keluskar, R., Nerurkar, A., Desai, A., 2013. Development of a simultaneous partial nitrification, anaerobic ammonia oxidation and denitrification (SNAD) bench scale process for removal of ammonia from effluent of a fertilizer industry. Bioresour. Technol. 130, 390-397.

Kim, K., Hur, J.W., Kim, S., Jung, J.Y., Han, H.S., 2020. Biological wastewater treatment: comparison of heterotrophs (BFT) with autotrophs (ABFT) in aquaculture systems. 
Bioresour. Technol. 296, 122293.

Lu, J., Jin, Q., He, Y.L., Wu, J., Zhao, J., 2008. Biodegradation of nonylphenol ethoxylates by Bacillus sp. LY capable of heterotrophic nitrification. FEMS Microbiol. Lett. 280 (1), 28-33.

Lu, J., Zhang, Y.X., Wu, J., Wang, J.H., Cai, Y., 2020. Fate of antibiotic resistance genes in reclaimed water reuse system with integrated membrane process. J. Hazard. Mater. 382,121025

Nhu Hien, N., Van Tuan, D., Nhat, P.T., Thi Thanh Van, T., Van Tam, N., Xuan Que, V.O.N., Phuoc Dan, N., 2017. Application of oxygen limited autotrophic nitritation/ denitrification (OLAND) for anaerobic latex processing wastewater treatment. Int. Biodeterior. Biodegrad. 124, 45-55.

Persson, F., Sultana, R., Suarez, M., Hermansson, M., Plaza, E., Wilen, B.M., 2014. Structure and composition of biofilm communities in a moving bed biofilm reactor for nitritation-anammox at low temperatures. Bioresour. Technol. 154, 267-273.

Shao, S., Hu, Y., Cheng, J., Chen, Y., 2019. Action of oxytetracycline (OTC) degrading bacterium and its application in Moving Bed Biofilm Reactor (MBBR) for aquaculture wastewater pre-treatment. Ecotoxicol. Environ. Saf. 171, 833-842.

Thakur, I.S., Medhi, K., 2019. Nitrification and denitrification processes for mitigation of nitrous oxide from waste water treatment plants for biovalorization: challenges and opportunities. Bioresour. Technol. 282, 502-513.

Wang, G., Xu, X.C., Gong, Z., Gao, F., Yang, F.L., Zhang, H.M., 2016. Study of simultaneous partial nitrification, ANAMMOX and denitrification (SNAD) process in an intermittent aeration membrane bioreactor. Process Biochem. 51 (5), 632-641.

Wang, J., Lu, J., Zhang, Y., Wu, J., Zhang, C., Yu, X.B., Zhang, Z.H., Liu, H., Wang, W.H., 2018a. High-throughput sequencing analysis of the microbial community in coastal intensive mariculture systems. Aquacult. Eng. 83, 93-102.

Wang, J., Lu, J., Zhang, Y., Wu, J., Luo, Y., Liu, H., 2018b. Metagenomic analysis of antibiotic resistance in coastal industrial mariculture systems. Bioresour. Technol. 253, 235-243.

Wang, J., Lu, J., Wu, J., Zhang, Y., Zhang, C., 2019a. Proliferation of antibiotic resistance genes in coastal recirculating mariculture system. Environ. Pollut. 248, 462-470.

Wang, S.Y., Zhu, G.B., Zhuang, L.J., Li, Y.X., Liu, L., Lavik, G., Berg, M., Liu, S., Long, X.E., Guo, J.H., Jetten, M., Kuypers, M., Li, F.B., Schwark, L., Yin, C.Q., 2019b. Anaerobic ammonium oxidation is a major $\mathrm{N}$-sink in aquifer systems around the world. ISME J. $1-13$.

Wang, Z., Huang, M.L., Qi, R., Zhang, Y.M., 2017. Enhancing nitrogen removal via the complete autotrophic nitrogen removal over nitrite process in a modified single-stage tidal flow constructed wetland. Ecol. Eng. 103, 170-179.

Wen, X., Zhou, J., Li, Y.C., Qing, X.X., He, Q., 2016. A novel process combining simultaneous partial nitrification, anammox and denitrification (SNAD) with denitrifying phosphorus removal (DPR) to treat sewage. Bioresour. Technol. 222, 309-316.

Zhang, X.J., Li, D., Liang, Y.H., Zhang, Y.L., Fan, D., Zhang, J., 2013. Application of membrane bioreactor for completely autotrophic nitrogen removal over nitrite (CANON) process. Chemosphere 93 (11), 2832-2838.

Zhang, Y.X., Lu, J., Wu, J., Wang, J.H., Luo, Y.M., 2020. Potential risks of microplastics combined with superbugs: enrichment of antibiotic resistant bacteria on the surface of microplastics in mariculture system. Ecotoxicol. Environ. Saf. 187, 109852.

Zhao, J., Feng, L.J., Yang, G.F., Dai, J.C., Mu, J., 2017. Development of simultaneous nitrification-denitrification (SND) in biofilm reactors with partially coupled a novel biodegradable carrier for nitrogen-rich water purification. Bioresour. Technol. 243, 800-809.

Zheng, Z.M., Huang, S., Bian, W., Liang, D.B., Wang, X.J., Zhang, K., Ma, X.R., Li, J., 2019. Enhanced nitrogen removal of the simultaneous partial nitrification, anammox and denitrification (SNAD) biofilm reactor for treating mainstream wastewater under low dissolved oxygen (DO) concentration. Bioresour. Technol. 283, 213-220.

Zheng, Z.M., Li, J., Ma, J., Du, J., Bian, W., Li, Y., Zhang, Y.Z., Zhao, B.H., 2016. Nitrogen removal via simultaneous partial nitrification, anammox and denitrification (SNAD) process under high DO condition. Biodegradation. 27, 195-208. 